\title{
Correction to: Soil microbes that may accompany climate warming increase alpine plant production
}

\author{
Joshua S. Lynn ${ }^{1,2,3}$ (D) Danielle A. Duarte ${ }^{1}$ Jennifer A. Rudgers ${ }^{1,2}$
}

Published online: 6 November 2019

๑) Springer-Verlag GmbH Germany, part of Springer Nature 2019

\section{Correction to: Oecologia \\ https://doi.org/10.1007/s00442-019-04518-6}

The DOI link to the data in the Acknowledgments section of the article was incorrect. The proper link to the data is: https://doi.org/10.6073/pasta/7c493a1d737f81905a41a8163 $0695 f 14$.

The original article can be found online at https://doi.org/10.1007/ s00442-019-04518-6.

Joshua S. Lynn

Joshua.Lynn@uib.no

1 Department of Biology, University of New Mexico, Albuquerque, NM 87131, USA

2 The Rocky Mountain Biological Laboratory, Gothic, CO 81224, USA

3 Present Address: Department of Biological Science, University of Bergen, 5006 Bergen, Norway 